\title{
HEPATITIS B VIRUS AND UNDERGRADUATE STUDENTS: A STUDY ON LEVELS OF AWARENESS IN UNIVERSITIES ACROSS KARACHI
}

\author{
Mukkaram Ali', Fauzia Imtiaz ${ }^{2}$, Muhammad Ahsan Rehman Khan ${ }^{3}$, Zaeem-ur-Rehman Khan $^{3}$, Bilal Ahmad ${ }^{3}$, \\ Muhammed Umer ${ }^{3}$, Soubia Akhtar ${ }^{3}$, Tayyaba Naeem Malhi ${ }^{3}$
}

${ }^{1}$ Department of Forensic Medicine, Dow University of Health Sciences

${ }^{2}$ Department of Biochemistry, Dow University of Health Sciences

${ }^{3}$ Student, Dow Medical College, Dow University of Health Sciences

Correspondence: Muhammad Ahsan Rehman Khan, Email: ahsan1rehman@yahoo.com

\begin{abstract}
Background: To assess awareness levels of Hepatitis B virus infection, transmission, treatment and prevention in medical and nonmedical students of Karachi.

Methods: Undergraduate students in 6 medical and non-medical universities were randomly approached to fill out a questionnaire. A sample size of 530 students was collected and data was analyzed using SPSS 20 software and chisquare tests for significance.

Results: Of the 530 students interviewed, 361(68.1\%) and 169(31.9\%) were identified as medical and non-medical students respectively. Significantly greater knowledge on modes of transmission were noted in medical students as well as overall levels of awareness of Hepatitis B virus, $(p=0.001)$ and $(p=0.003)$ respectively.

Conclusion: Both medical and non-medical students showed a moderate level of awareness of Hepatitis $B$ virus, its modes of transmission, treatment and preventive measures. Medical students showed an overall greater level of awareness.
\end{abstract}

Keywords: Hepatitis B, awareness, undergraduate, medical, non-medical, students

\section{Introduction}

Hepatitis virus infections mainly affect the liver and can lead to significant morbidity and mortality. Globally, 2 billion people suffer from Hepatitis B virus (HBV) infections of which 360 million develop a chronic course of illness, remaining an ever-existent source of further infection.(1)

According to a national survey $7.4 \%$ of Pakistan's entire population, over 11 million cases were tested positive for Hepatitis $B$ and $C$ infections.(2) The exposure rate of HBV has been $35-38 \%$ with $4 \%$ being carriers (3), the reasons for which may include poor economic status, lack of proper health facilities and poor public awareness about the transmission of major communicable diseases including HBV, HCV, and HIV. (4)

Undergraduate students constitute a significant section of the population under threat of getting infected. During the course of clinical work, medical students are often in direct contact with patients, injections, blood and surgical instruments, along with undesirable accidents happening during the initial period of practical training, and due to lack of experience and professional skills, all of which increase the risk of infection. (5) Prevalence of HBV in students in health related sectors has been reported as high as $5 \%$, double the average $2.4 \%$ rate.(2,6) No specific research has calculated prevalence rates amongst non-medical students however, numerous studies have demonstrated low levels of knowledge on transmission and prevention practices amongst this group.(7) In addition to this, very few studies have compared levels of awareness between medical and non-medical students.

This presented study was conducted to assess the levels of awareness of HBV in undergraduate students of medical and non-medical programs in different institutions of Karachi.

Methodology

A cross-sectional study on awareness of hepatitis infections, specifically hepatitis B was conducted amongst undergraduate students enrolled in medical and non-medical programs of six private and public universities of Karachi. They were approached randomly and asked to fill a preformed questionnaire from June to October 2016. The inclusion criteria was any student currently enrolled in an undergraduate program. No restriction on gender or age was made. Exclusion criteria included everyone who did not fall in the inclusion criteria or did not complete the questionnaire.

The sample size was 530 which were calculated by online software OpenEpi 3.0. The data was analyzed 
using SPSS 20.0 software. Chi-square tests were done to check for significance $(p<0.05)$ using a confidence level of $95 \%$.

\section{Results}

Of the completed 530 questionnaires, male and female ratio was nearly $1: 1$ with majority of students $392(74 \%)$ falling in the age group $20-23$ years. $361(68.1 \%$ ) were medical students while $169(39.1 \%)$ were enrolled in non-medical programs. (Table 1).

Table 1. Demographic characteristics of the study population

\begin{tabular}{|c|c|c|c|}
\hline Variable & Characteristic & Frequency & Percentage \\
\hline \multirow{2}{*}{ Gender } & Male & 273 & $51.5 \%$ \\
\cline { 2 - 4 } & Female & 257 & $48.5 \%$ \\
\hline & & & \\
\hline \multirow{3}{*}{ Age(years) } & $16-19$ & 124 & $23.4 \%$ \\
\cline { 2 - 4 } & $20-23$ & 392 & $74.0 \%$ \\
\cline { 2 - 4 } & $24-27$ & 14 & $2.6 \%$ \\
\hline \multirow{2}{*}{ Program } & Medical & 361 & $68.1 \%$ \\
\cline { 2 - 4 } & Non-medical & 169 & $31.9 \%$ \\
\hline Total & & 530 & $100 \%$ \\
\hline
\end{tabular}

Results were tabulated and percentages calculated. The questions asked from each participant were grouped into categories as Basic knowledge, Modes of transmission and Treatment \& prevention (Table 2). Overall awareness averages were calculated (Figure 1) along with percentages of correct responses in each category. (Figure 2).

\section{Overall awareness}

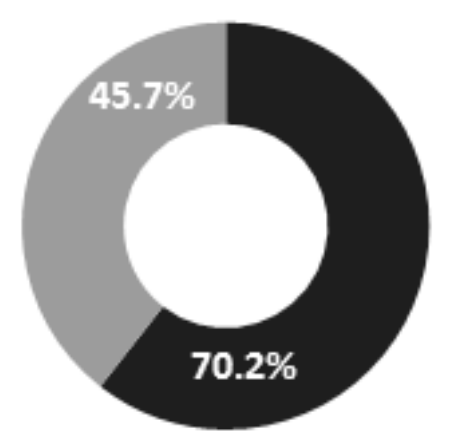

- Program Medical

- Program Non-medical

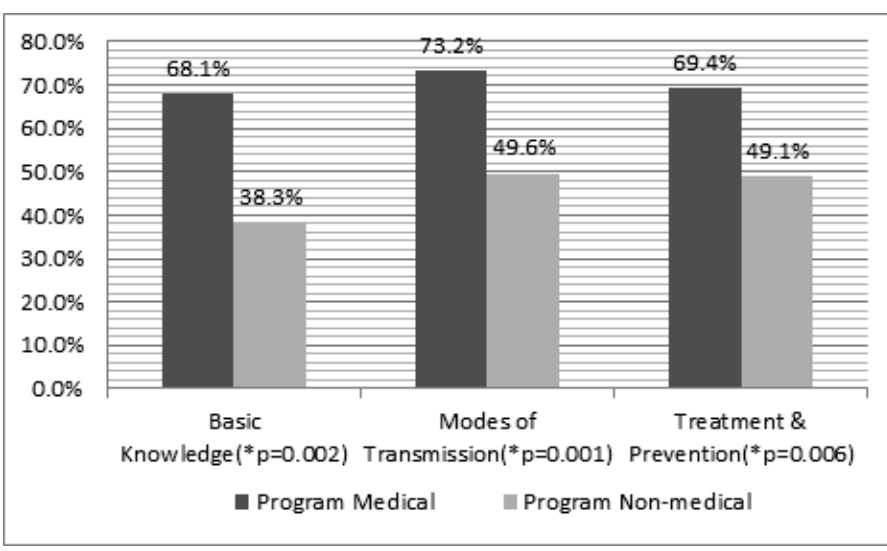

Figure 2. Percentage of correct responses in major categories

Medical students largely identified more than 3 types of hepatitis $289(80.1 \%)$ while only $57(33.7 \%$ ) of nonmedical students gave a similar answer. On the whole, there was a significant difference, $p=0.002$, between medical and non-medical students when comparing their basic knowledge of hepatitis infections.

Most, $(86.7 \%)$ and $(89.5 \%)$ of medical students identified non-sterile dental instrument use for tooth extraction procedures and sharing needles for ear piercing, respectively, as possible modes of transmission of Hepatitis B in comparison to $104(61.5 \%)$ and $91(54.8 \%)$ non-medical students respectively. Transmission from mother to baby during delivery was correctly identified by $290(80.3 \%)$ medical and $90(53.8 \%)$ non-medical students. A large number of students from both medical $347(96.1 \%)$ and nonmedical $119(70.4 \%)$ programs positively identified unscreened blood transfusions as a possible source of infection. Overall, a significant difference, $p=0.001$, was noticed regarding knowledge on various modes of transmission.

Vaccines were identified as the best method of prevention by $285(78.9 \%)$ medical and $90(54.5 \%)$ nonmedical students. $264(73.1 \%)$ of medical students recommended infancy as the ideal age for vaccination while $97(26.9 \%)$ opted for youth or adulthood. $101(59.8 \%)$ of non-medical students preferred infancy over youth and adulthood. 291(80.6\%) and $94(55.6 \%)$ of medical and non-medical students respectively, agreed that the vaccine was available in the city of Karachi. Overall, difference in knowledge of treatment, prevention and vaccinations was significant, $p=0.006$, amongst the two groups of students.

Overall, using Chi-square test, the difference in levels on awareness of Hepatitis B amongst medical and nonmedical students was found to be significant, $p=0.003$.

Figure 1. Percentage awareness of both the medical and non-medical participants 
Table 2. Knowledge of Hepatitis B among the study participants

\begin{tabular}{|c|c|c|c|c|}
\hline & \multirow[b]{2}{*}{ Variable } & \multicolumn{2}{|c|}{ Program } & \multirow{2}{*}{$\begin{array}{c}\text { P- } \\
\text { values }\end{array}$} \\
\hline & & Medical & $\begin{array}{c}\text { Non- } \\
\text { medical }\end{array}$ & \\
\hline \multirow{3}{*}{$\begin{array}{c}\text { Basic } \\
\text { Knowlegde }\end{array}$} & Types of Hepatitis & $289(80.1 \%)$ & $57(33.7 \%)$ & \multirow{3}{*}{0.002} \\
\hline & Most common type in Karachi & $209(57.9 \%)$ & $83(49.1 \%)$ & \\
\hline & $\begin{array}{l}\text { Greater susceptibility of infection in medical } \\
\text { personnel }\end{array}$ & $239(66.2 \%)$ & $54(32.0 \%)$ & \\
\hline \multirow{10}{*}{$\begin{array}{l}\text { Modes of } \\
\text { Transmission }\end{array}$} & Commonly associated risk factor & $234(64.8 \%)$ & $66(39.1 \%)$ & \multirow{10}{*}{0.001} \\
\hline & Possibility of having HIV with HepB infection & $303(83.9 \%)$ & $88(52.7 \%)$ & \\
\hline & Is HepB contagious & $236(65.4 \%)$ & $79(47.3 \%)$ & \\
\hline & Should HepB patient be allowed to work & $203(56.2 \%)$ & $53(34.3 \%)$ & \\
\hline & Transferred from mother to baby during delivery & $290(80.3 \%)$ & $91(53.8 \%)$ & \\
\hline & Should HepB mothers be allowed to breastfeed & $90(24.9 \%)$ & $29(17.2 \%)$ & \\
\hline & Spread using non-sterile dental instruments & $313(86.7 \%)$ & $104(61.5 \%)$ & \\
\hline & Spread through sharing of needles for ear piercings & $332(89.5 \%)$ & $94(54.8 \%)$ & \\
\hline & Spread through unscreened blood transfusions & $347(96.1 \%)$ & $119(70.4 \%)$ & \\
\hline & Spread through unprotected sexual intercourse & $302(83.7 \%)$ & $110(65.1 \%)$ & \\
\hline \multirow{9}{*}{$\begin{array}{c}\text { Treatment \& } \\
\text { Prevention }\end{array}$} & $\begin{array}{l}\text { Should testing of all patients for disease be } \\
\text { mandatory }\end{array}$ & $304(84.2 \%)$ & $115(68.0 \%)$ & \multirow{9}{*}{0.006} \\
\hline & Ever been diagnosed with any liver disease & $41(11.4 \%)$ & $21(12.4 \%)$ & \\
\hline & Is HepB an incurable disease & $262(72.6 \%)$ & $87(51.5 \%)$ & \\
\hline & Is HepB a fatal disease & $219(60.7 \%)$ & $91(53.8 \%)$ & \\
\hline & Effectiveness of its vaccine & $317(87.8 \%)$ & $93(55.0 \%)$ & \\
\hline & Ever received any HepB vaccine & $373(75.6 \%)$ & $53(31.4 \%)$ & \\
\hline & Ideal age for vaccination & $264(73.1 \%)$ & $101(59.8 \%)$ & \\
\hline & Vaccine currently available in your city & $291(80.6 \%)$ & $94(55.6 \%)$ & \\
\hline & Best way to prevent infection & $285(78.9 \%)$ & $90(54.5 \%)$ & \\
\hline
\end{tabular}

\section{Discussion}

Hepatitis B infections are a major health problem globally, leading to a tremendous burden on health care systems and remain a major source of patient's misery. $(8,9)$ It is mostly transmitted parentally through sharing of needles, injury from contaminated sharp instruments, unprotected sexual contact, and through perinatal transmission from mother to child.(10) It is a leading cause of chronic liver disease (CLD) and hepatocellular carcinoma which can lead to significant morbidity and mortality. $(11,12)$ According to a study, $30.35 \%$ of patients of CLD in a hospital in Abbottabad tested positive for HBV.(13) Awareness studies focused on the general populace's levels of knowledge and preventive measures are therefore of paramount importance in formulating a plan of action to minimize the adverse effects of these diseases and to limit its spread. The overall awareness levels were fair while significant room for improvement amongst nonmedical students was identified. These results were slightly lower than a study conducted in Lahore14 and similar with another done in Saudi Arabia. 15 Basic knowledge of students in this study was considerably lower than those conducted in Hyderabad 16, India17 and Egypt.18

Higher levels of knowledge of modes of transmission were seen amongst both groups of students in comparison to basic and preventative measures. A majority of non-medical students correctly identified using non-sterile dental instruments and unprotected sexual intercourse as possible modes of transmission consistent with findings in studies conducted in studies in Karachi19 and Hong Kong20 while most medical students along with the above mentioned means also identified sharing of needles for piercing and vertical transmission from mother to child as potential methods of spread of disease similar to results in surveys in Saudi
Arabia2, Pakistan21, India17, Ethiopia22 and Morocco23. Both groups positively identified unscreened blood transfusions as a source of HBV spread.24 Interestingly, $56.1 \%$ of participants considered breastfeeding by HBV infected mothers to be not safe, similar to the $55 \%$ found in a study in Hongkong.20 Overall, the knowledge of non-medical students was found to be significantly lower than those enrolled in medical programs thus emphasizing a need for further resources and attention to be given for the awareness of these students.

Awareness levels of treatment and prevention of HBV was found to be fair amongst both medical and nonmedical students. Most students positively endorsed the effectiveness of the vaccine as a preventative tool and correctly identified its availability in their city. These results were considerably better than a study conducted in Saudi Arabia15 and Lahore14 while similar to those done in Greece25 and Africa.26 An improvement in levels of vaccine awareness can be argued to be due to the introduction of the vaccine at the level of antenatal care as a part of the Extended Program of Immunization (EPI) in 2009 . This may also be the reason why $73.1 \%$ and $59.8 \%$ (medical and non-medical respectively) chose infancy as the ideal age for vaccination. Similar or slightly lower percentages of medical students confirmed ever receiving any dose of vaccination in comparison to the following studies.17,27,28 However, this study revealed significantly lower levels of nonmedical students who received any vaccine in comparison to studies showing students in similar demographics who had either received the vaccine or were willing to do so.(14)

\section{Conclusion}

The comparison of awareness levels of Hepatitis viruses especially Hepatitis B, amongst medical and nonmedical undergraduate students in Karachi showed moderate levels of knowledge in both groups of students with non-medical students scoring significantly lower in all areas of the study. In comparison to past studies, while some positive trends were observed such as more awareness of vaccines as a tool of protection, a greater necessity towards educating students on methods of transmission and basic understanding of HBV is much needed to clear the misconceptions such as safety of breastfeeding identified through this study.

Lastly, efforts need to be made to bridge the significant difference in awareness levels observed between medical and non-medical students throughout the study.

\section{References}

1 Shepard CW, Simard EP, Finelli L, Fiore AE, Bell BP. Hepatitis B virus infection: epidemiology and vaccination. Epidemiol Rev 2006;28:112-25.

2 Firas AG, Faisal AA, Abdulrahman SA, Abdullah SA, Waleed KA, Khalid AA. Medical students' awareness of and compliance with the hepatitis $B$ vaccine in a tertiary care academic hospital: An epidemiological study. Journal of Infection and 
Public Health [Internet]. 2016; 9(1): 60 - 65. Available from: http://www.jiph.org/ article/S1876-0341(15)00133-1/fulltext DOI: http://dx.doi.org/10.1016/j.jiph.2015.06.008 Hakim ST, Kazmi SU, Bagasra O. Seroprevalence of hepatitis $B$ and $C$ genotypes among young apparently healthy females of Karachi, Pakistan. Libyan J Med. 2008; 3:66-70. Alam MM, Zaidi SZ, Malik SA, Naeem A, Shaukat S, Sharif S, et al. Serology based disease status of Pakistani population infected with hepatitis B virus. BMC Infect Diseases. 2007; 7:64.

5 Osborn, E. H., M. A. Papadakis, and J. L. Gerberding. Occupational exposures to body fluids among medical students. A seven-year longitudinal study. Annals of internal medicine 130 (1):45-51.1999.

6 S. Aziz,H. I. Tily,K. Rasheed, A. Memon, K. Jehangir, M. S. Quraishy. Prevalence of H1V, Hepatitis B and C amongst Health Workers of Civil Hospital Karachi. JPMA, March 2002. Available from: http://www.jpma.org.pk/ full_article_text.php?article_id=2142

$7 \quad$ Ali Rafiq, Saba Fatima, Beenish Masood, Rizwan Ahmed Khan, Fareeha Ahmed Khan, Aimen Liaquat, Aelia Fatima. Awareness of hepatitis $B$ and $C$ among students of nonmedical universities in Karachi. Asian Biomedicine Vol. 9 No. 2 April 2015; 155-159.

8 Pokorski RJ. Cost/benefit of laboratory tests. J. Insur Med. 2006; 38: 31-43.

9 Wong JB. Hepatitis C: cost of illness and considerations for the economic evaluation of antiviral therapies. Pharmacoeconomics. 2006; 24: 661-672.

10 Kamal GI. 2000. Pathogenic features of chronic hepatitis. Am J Clin Pathol. 113: 40-55.

11 Perz JF et al. The contributions of hepatitis B virus and hepatitis $C$ virus infections to cirrhosis and primary liver cancer worldwide. Journal of Hepatology, June 2006, 45:529-38.

12 Abdul Mujeeb S, Jamal Q, Khanani R, Iqbal N, Kaher S. 1997. Prevalence of hepatitis B surface antigen and HCV antibodies in hepatocellular carcinoma cases in Karachi, Pakistan. Trop Doct. 27: 45-46.

13 Khan TS, Rizvi F. HEPATITIS B SEROPOSITIVITY AMONG CHRONIC LIVER DISEASE PATIENTS IN HAZARA DIVISION PAKISTAN. J Ayub Med Coll Abbottabad. June 2003;15(2):53-5.

14 RaziA, Rehman R, Naz S, Ghafoor F, Khan MA. KNOWLEDGE ATTITUDE AND PRACTICES OF UNIVERSITY STUDENTS REGARDING HEPATITIS B AND C. ARPN Journal of Agricultural and Biological Science. July 2010; 5(4): 38-43.
Al-Jabri AA, Al-Adawi S, Al-Abri JH, Al-Dhahry $\mathrm{SH}$. Awareness of hepatitis $\mathrm{B}$ virus among undergraduate medical and non-medical students. Saudi Med J. April 2004; 25(4): 484-7. Nusrat Nisar, Raheel Baloach, Aftab Afroz Munir. Does clinical experience affect knowledge regarding Hepatitis- $B$ among male medical students at a private university? J Pak Med Assoc. Vol. 59, No. 12, December 2009

Singh A, Jain S. Prevention of Hepatitis BKnowledge and Practices Among Medical Students. Indian Medical Gazette. Feb 2012; 5256. Available from: http://medind.nic.in/ice/ t12/i2/icet12i2p52.pdf

Naglaa A. El Sherbiny1 \& Asmaa Younis1 \& Mohamed Masoud1 Assessment of hepatitis knowledge and attitudes among Fayoum University students: a cross-sectional study, Fayoum, Egypt. J Public Health (2016) 24:101106

Khan SJ, Anjum Q, Khan N, Ghulam Nabi F. riginal Article Awareness about Common Diseases in selected Female College Students of Karachi. JPMA. 2005;55:195. Available from: https://www.researchgate.net/publication/2512 24194_Original_Article_Awareness_about_Co mmon_Diseases_in_selected_Female_College Students_of_Karachi

$\bar{C} M$ Leung, $\overline{W H}$ Wong, KH Chan, Lawrence SW Lai, YW Luk, JY Lai, YW Yeung, WH Hui. Public awareness of hepatitis B infection: apopulationbased telephone survey in Hong Kong. Hong Kong Med J 2010;16:463-9

Anjum Q, Siddiqui H, Ahmed Y, Rizvi SR, Usman Y. Knowledge of Students regarding Hepatitis and HIVIAIDS of a Private Medical University in Karachi. J Pak Med Assoc. July 2005; 55(7): 258. Available from: http://jpma.org.pk/full_ article_text.php?article_id $=783$

Abdnūr Abdela, Berhanu Woldu, Kassahun Haile, Biniam Mathewos and Tekalign Deressa* Assessment of knowledge, attitudes and practices toward prevention of hepatitis $B$ virus infection among students of medicine and health sciences in Northwest Ethiopia. (2016) 9:410DOI 10.1186/s13104-016-2216-y

K. Djeriri1, H. Laurichesse2,3, J. L. Merle1, R. Charof4, A. Abouyoub5, L. Fontana. Hepatitis B in Moroccan health care workers. Occupational M e dic in e 2008;58:419-424. doi:10.1093/occmed/kqn071

Rajiv Saini, Santosh Saini1, R. S. Sugandha2. Knowledge and awareness of Hepatitis B infection amongst the students of Rural Dental College, Maharashtra, India. Annals of Nigerian Medicine / Jan-Jun 2010 / Vol 4 | Issue 1

Georgia Gioula, Thomas Vasilakis, Dimitra Vassiliadou, Kyriakos Xanthopoulos, Eirini 
Triantafyllaki, Vasiliki Kyriazopoulou-Dalaina. Knowledge of medical students about Hepatitis B. Aristotle University Medical Journal, Oct 2008 Vol. 35, Issue 3.

26 Bridget Malewezi, Saad B. Omer, Beatrice Mwagomba, Trish Araru. Protecting health workers from nosocomial Hepatitis B infections: A review of strategies and challenges for implementation of Hepatitis $B$ vaccination among health workers in Sub-Saharan Africa. Journal of Public Health in Africa, 2016; Vol. 7:553.

27 Hussain S, Patrick NA, Shams R. Hepatitis B and $C$ Prevalence and Prevention Awareness among Health Care Workers in a Tertiary Care Hospital. International Journal of Pathology. 2010; 8(1): 16-21. Available from: https://www.researchgate.net/publication/2284 81941_Hepatitis_B_and_C_Prevalence_and Prevention_Awareness_among_Health_Care_ Workers_in_a_Tertiary_Care_Hospital

28 Nazeer Khan, Sheikh Munir Ahmed, Muhammad Masood Khalid, Sarah Hasan Siddiqui, Ayesha Altaf Merchant. Effect of gender and age on the knowledge, attitude and practice regarding Hepatitis $B$ and $C$ and vaccination status of Hepatitis B among medical students of Karachi, Pakistan. J Pak Med Assoc, Vol. 60, No. 6, June 2010 